\title{
Muscle, exercise and arthritis
}

\section{V Hurley}

\section{The importance of (everyone) being earnest}

Earnest: determined, assiduous, sincere, heartfelt, well meant, diligent, hard working, conscientious, committed. Of persons: Serious in purpose, feeling, convictions or action-for example, she made an earnest promise to do her best. Of words or actions: proceeding from intense convictions-for example, he said he would help, but I doubt whether he was in earnest.

\section{"The way we currently manage elderly patients is inappropriate, inefficient and wasteful"}

Osteoarthritis (OA) can affect all intra-articular and periarticular tissues comprising synovial joints (bone, cartilage, muscle, nerves, etc). The aetiology of OA is complex and multifactorial but, recently, muscle sensorimotor dysfunction (muscle weakness, increased fatigability, proprioceptive deficits) has been implicated in the pathogenesis of OA, by impairing neuromuscular protective mechanisms that prevent harmful abnormal joint movement, damage, and pain. ${ }^{1}$ These arguments have largely been based on studies investigating the knee and vertebral column musculature, the hip muscles have received less research attention, probably because of difficulties in isolating, examining, and interpreting the results. In this issue of the Annals of the Rheumatic Diseases, however, Sims et al extend our knowledge in this area, reporting a study investigating muscle motor function in patients with unilateral hip OA. ${ }^{2}$

Investigating muscle involvement in $\mathrm{OA}$ is a pointless, academic exercise if it has no clinical application, but of all the synovial joint tissues affected by OA, muscle is the tissue we can most easily manipulate. In patients with established OA simple exercise regimens requiring inexpensive, unsophisticated equipment improve muscle function, joint pain and stability, function and disability. ${ }^{1{ }^{3}}$ More speculatively, maintaining well conditioned muscle might provide us with a strategy to prevent primary or secondary joint damage.

So exercise affords us an efficacious, safe, low tech, low cost treatment, available to the large population of patients who need it, when they need it. What more can cash strapped patients, healthcare providers, governments, and tax payers ask? Not a lot according to the ACR and EULAR, whose evidence based guidelines endorse the early use of exercise in the management of knee OA. ${ }^{56}$ Why then do so few patients receive adequate advice about exercise, still fewer are referred for physiotherapy, only a tiny minority benefit from effective rehabilitation regimens, and virtually nobody has access to facilities necessary to encourage long term compliance with regular exercise? The answer to this conundrum is complex but addressing it is essential if we are to manage this increasingly prevalent condition effectively and efficiently.

\section{Health beliefs, attitude, and management of OA}

The general attitude toward OA is one of defeated resignation. Healthcare professionals, patients, and the lay population regard $\mathrm{OA}$ as an inevitable consequence of life, resulting in a slow, relentless deterioration, which is not only incurable but also virtually untreatable. Most rheumatologists are more interested in more "challenging", esoteric conditions.

\section{"Most doctors have a serious drug habit!"}

Most general practitioners are similarly uninterested in benign joint pains and overwhelmed by more pressing problems. Most doctors have a serious drug habit! Consequently, patients are inappropriately maintained with expensive, potentially harmful, palliative drug treatment ${ }^{7}$ until the pain becomes so disabling that they are referred for surgery, which after a lengthy wait they may undergo if they are not too old, or too young, or don't have common surgical contraindications. ${ }^{8} 9$ Everyone knows they need rehabilitation to help with this drug habit, but rehabilitation is difficult to obtain and, as currently delivered, provides only transient benefit. For patients this management regimen is unhelpful and unsatisfactory, but it reinforces their poor understanding, health beliefs, and fatalistic view of OA.
Despite the evidence demonstrating the efficacy of exercise, less than half of patients with rheumatic conditions report receiving exercise advice. ${ }^{10}$ Either we are unconvinced by this evidence, or give exercise a low priority in patient management, or we get fed up with hearing ourselves advising/nagging/ telling patients to do seemingly pointless, impractical exercises, so we end up saying nothing or giving half-hearted advice. Compounding this, virtually no resources are allocated to helping and encouraging patients to exercise. It is not surprising that exercise is seen as having a very low priority, unimportant, not worth spending resources on, not worth recommending to patients, and not worth patients pursuing.

\section{Burden of the disease}

Not only are we all underwhelmed by this "mundane" condition, but the size of the problem is overwhelming. ${ }^{11}$ To create an unsustainable demand for treatment of such a prevalent, progressive, but non-life threatening, condition seems to be folly. Unfortunately, the enormous personal, social, and economic burdens of OA are about to get a great deal bigger as more people live longer. Solutions, even partial solutions, must be found to maximise the quality of people's lives, their independence, and the efficient use of finite healthcare resources.

\section{Knowledge of exercise for OA}

Patients and healthcare professionals are very confused about the place exercise has in the management of OA. Most people intuitively appreciate that joints were made to move and muscles to work, and to patients living with weak easily fatigued muscles and painfully, stiff unstable joints the benefits of physical activity are readily appreciated. Countering these appropriate health beliefs, activity is associated with onset and increase in joint pain, and rest with pain relief. In addition, human joints are equated with mechanical joints that often fail with continued use. In the absence of any reliable information and reassurance from us, people worry that movement will cause joint failure and that pain is signalling the start of this process, so they reduce their activities to prolong the life of their joints.

\section{You know it ain't easy}

The thing everyone knows about exercise is that it takes considerable time, hard work, and effort to attain benefits, and tremendous perseverance to retain these gains. This is exactly what we don't want to have to tell our patients and exactly what they don't want to hear. There is, however, no escaping the truth. 
As a consequence of erroneous health beliefs, confusion about the benefits and safety of exercise, half-hearted lipservice rather than clear convincing advice about what patients should (not) be doing, when and how, our patients are frozen into inactivity. This exacerbates their muscle weakness, joint stiffness, pain, and damage.

\section{THE WAY FORWARD: AN EXERCISE IN SELF MANAGEMENT}

To increase participation in exercise, the priority that exercise has in the management of OA and other rheumatic conditions must be increased. To achieve this we must replace defeatist attitudes and erroneous health beliefs about OA with a positive approach toward the management of OA, emphasising the vital role that exercise plays in patient self management.

\section{Get an attitude}

Healthcare professionals have a major responsibility to play in portraying the positive role that exercise plays in patient self management of $\mathrm{OA}^{12}$ and most other common rheumatic conditions-low back pain, ${ }^{13}$ ankylosing spondylitis, ${ }^{14}$ rheumatoid arthritis, ${ }^{15}$ juvenile idiopathic arthritis. ${ }^{1617}$ But we must first convince ourselves of the effectiveness and important role of exercise before we have any chance of convincing our patients of the need to implement burdensome lifestyle changes. The evidence for the effectiveness of exercise in the management of rheumatic diseases is convincing. Examine it.

\section{A word of advice}

Simply instructing people to perform seemingly pointless, impractical exercises will not get people exercising regularly. The advice we give must be clear, understandable, practical-taking into account people's functional limitations, and easily integrated into people's daily lives, consistent, and conveyed with whole hearted conviction. Exercise doesn't have to involve strenuous, lengthy sessions in a gym, 30 minutes of accumulated physical activity is as beneficial as a strenuous jog, but should be performed on most, preferably all, days of the week. ${ }^{18}$ This physical activity could be accumulated during three 10 minute brisk walks, 30 minutes' gardening or housework, or an enjoyable day out. For patients such advice is more achievable and acceptable than "going for the burn" in a gym. It is more likely to increase compliance and deliver the psychological benefits of exercise-increased feelings of self achievement, self confidence, self esteem, and personal independence. ${ }^{19}$ This advice should be consolidated with written instructions and patient information literature and repeated at every opportunity to reinforce the message. ${ }^{10}$
Ignoring the evidence demonstrating the effectiveness and importance of exercise and increased physical activity in the management of specific rheumatic conditions and general health benefits, and failing to recommend exercise to our patients, is professional negligence.

\section{Experientia docet-experience teaches}

Even when delivered with whole hearted conviction, advising people to exercise will only have a limited effect on increasing people's participation in regular physical activity. To get patients more physically active they must believe in the benefits of exercise and believe they have the ability to perform the exercises effectively. ${ }^{20}{ }^{21}$ To achieve this they need to experience the benefits of a simple, practicable, and enjoyable rehabilitation regimen that can easily be integrated into their daily lives, and must include specific advice about how to continue exercising at home or in the community.

\section{"Failure to recommend exercise to our patients is professional negligence"}

The way we currently manage elderly patients with chronic, variable, progressive conditions, who are struggling to maintain their independence in the community where many barriers hinder compliance, with advice to increase regular physical activity is inappropriate, inefficient, and wasteful. At present patients referred to physiotherapy usually receive a short course of palliative treatment where they are the passive recipient of modalities (electrotherapy, manual therapy, etc) and exercise advice, before being discharged. Follow up appointments to check, reinforce, and generate progression of their home exercise regimen are rare.

The most effective rehabilitation regimens integrate an exercise regimen into a programme of patient education and self management techniques-advice and information about problems caused by excess body weight, simple methods of pain control, joint protection, restactivity, cycling, etc. ${ }^{19}$ This helps patients to understand their condition better, how it affects them, and how they can help themselves. Direct personal experience helps patients appreciate the value of physical activity.

\section{Enabling self management}

Owing to the size of the population affected by chronic rheumatic diseases and limited financial and logistical resources, prolonged hospital based rehabilitation is all but impossible. To comply with advice to participate in regular physical activity and implement the self management skills learnt during a hospital based rehabilitation regimen, appropriate community based facilities must be available. Unfortunately, there are few facilities where people, especially the elderly, can go to implement the advice they receive and obtain the reassurance, support, and motivation from their peers and healthcare professionals that people with chronic episodic pain need in order to adopt and maintain healthy lifestyles. ${ }^{22}$ Faced with these barriers and lack of support people quickly become frustrated, demotivated, and stop exercising. Any health benefits attained from hospital based regimens quickly evaporate. To provide more efficient management of people with chronic rheumatic conditions requires more community facilities, better cooperation and coordination between health and social care and welfare agencies, and innovative ways of delivering and continuing support for people when they need it and where they need it. Only by doing this will we enable people to truly self manage themselves in the community.

Muscle is not the cause of all OA, nor is exercise a panacea for all its consequences. However, appreciating the role muscle and exercise in the aetiology and management of OA and other common rheumatic conditions presents us with an opportunity to influence the course of these increasingly prevalent conditions. It is incumbent on all healthcare professionals not to give uninterested, halfhearted exercise advice, but to convince people of the benefits of regular exercise and physical activity, and ensure they can follow our advice by demanding that the appropriate facilities and resources are available which will enable people to remain physically active. Only then will our patients have any chance of remaining earnest in their ability to implement our earnest advice.

Ann Rheum Dis 2002;61:673-675

\section{Author's affiliation}

M V Hurley, Rehabilitation Research Unit, Physiotherapy Division, King's College London, UK

Correspondence to Dr M V Hurley, King's College London, Rehabilitation Research Unit, King's Healthcare (Dulwich), East Dulwich Grove, London SE22 8PT, UK;

mike.hurley@kcl.ac.uk

\section{REFERENCE}

1 Hurley MV. The role of muscle weakness in the pathogenesis of osteoarthritis. Rheum Dis Clin North Am 1999;25:283-98.

2 Sims KJ, Richardson CA, Braver SG. Investigation of hip abductor activation in subjects with clinical unilateral hip osteoarthritis. Ann Rheum Dis 2002;61:687-92.

3 Minor MA. Exercise in the treatment of osteoarthritis. Rheum Dis Clin North Am 1999;25:397-415. 
4 van Baar ME, Assendelft WJJ, Dekker J, Oostendorp RAB, Bijlsma JWJ. Effectiveness of exercise therapy in patients with osteoarthritis of the hip and knee. A systematic review of randomized clinical trials. Arthritis Rheum 1999:42:1361-9.

5 Altman RD, Hochberg MC, Moskowitz RW, Schnitzer TJ. Recommendations for the medical management of osteoarthritis of the hip and knee. Arthritis Rheum 2000:43: 1905-15.

6 Pendleton A, Arden N, Dougados $M$, Doherty M, Bannwarth B, Biilsma JWJ, et al. EULAR recommendations for the management of knee osteoarthritis: report of a task force of the Standing Committee for International Clinical Studies Including Therapeutic Trials (ESCISIT). Ann Rheum Dis 2000;59:936-44.

7 Hochberg MC, Chang RW, Dwosh I, Linsey S, Pincus T, Wolfe F. The American College of Rheumatology 1991 revised criteria for the classification of global functional status in rheumatoid arthritis. Arthritis Rheum 1992;35:498-502.

8 Dieppe $\mathbf{P}$, Basler HD, Chard J, Croft P, Dixon $J$, Hurley $M$, et al. Knee replacement surgery for osteoarthritis: effectiveness, practice variations, indications and possible determinants of utilization. Rheumatology (Oxford) 1999;38:73-83.

9 Tennant A, Fear J, Pickering A, Hillman M, Cutts A, Chamberlain MA. Prevalence of knee problems in the population aged 55 years and over: identifying the need for arthroplasty. BM 1995;310:1291-3.

10 Dexter PA. Joint exercises in elderly persons with symptomatic osteoarthritis of the hip or knee. Performance patterns, medical support, and the relationship between exercising and medical care. Arthritis Care Res 1992;5:36-41.

11 Badley E, Rasooly I, Webster GK. Relative importance of musculoskeletal disorders as a cause of chronic health problems, disability, and health care utilization: findings from the 1990 Ontario Health Survey. J Rheumato 1994;21:505-14.

12 Andersen RE, Blair SN, Cheskin LJ, Bartlett SJ. Encouraging patients to become more physically active: the physician's role. Ann Intern Med 1997; 127:395-400.

13 van Tulder $M$, Malmivaara A, Esmail R, Koes B. Exercise therapy for low back pain. A systematic review within the framework of the Cochrane Collaboration Back Review Group. Spine 2002;25:2784-96.

14 Uhrin Z, Kuzis S, Ward MM. Exercise and changes in health status in patients with ankylosing spondylitis. Archiv Intern Med 2000; 160:2969-75

15 Van den Ende CHM, Vliet Vlieland TPM Munneke M, Hazes JM. Dynamic exercise therapy in rheumatic arthritis: a systematic review. Br J Rheumatol 1998;37:677-87.
16 Kirchheimer JC, Wanivenhaus A, Engel A. Does sport negatively influence joint scores in patients with juvenile rheumatoid arthritis. An 8 -year prospective study. Rheumatology Int 1993; 12:239-42.

17 Klepper S. Effects of an eight-week physical conditioning program on disease signs and symptoms in children with chronic arthritis. symptoms in children with chronic
Arthritis Care Res 1999; 12:52-60.

18 Pate RR, Pratt M, Blair SN, Haskell WL Macera CA, Bouchrad C, et al. Physical activity and public health. A recommendation from the centers for disease control and prevention and the American College of

19 Keefe FJ, Kashikar-Zuck S, Opiteck J, Hage E, Dalrymple L, Blumenthal JA. Pain in arthritis and musculoskeletal disorders: the role of coping skills training and exercise interventions. J Orthop Sports Phys The 1996:24:279-90

20 McAuley E, Lox C, Duncan TE. Long-term maintenance of exercise, self-efficacy, and physiological change in older adults. J Gerontol B Psychol Sci Soc Sci 1993:48:218-24.

21 Rejeski WJ, Ettigner WH, Martin K, Morgan $T$. Treating disability in knee osteoarthritis with exercise: a central role for self-efficacy and pain. Arthritis Care Res 1998;11:94-101.

22 Hillsdon. Randomized controlled trials of physical activity promotion in free living populations: a review. J Epidemiol Community Health 1995;49:448-53. 